\title{
Validation of criterion-based patient assignment and treatment effectiveness of a multidisciplinary modularized managed care program for headache
}

\author{
Thomas-Martin Wallasch • Christiane Hermann
}

Received: 23 March 2012/Accepted: 16 April 2012/Published online: 13 May 2012

(C) The Author(s) 2012. This article is published with open access at Springerlink.com

\begin{abstract}
This prospective observational study evaluates the validity of an algorithm for assigning patients to a multidisciplinary modularized managed care headache treatment program. $N=545$ chronic headache sufferers [migraine $(53.8 \%)$, migraine + tension type $(30.1 \%)$, tension type $(8.3 \%)$ or medication overuse headache $(6.2 \%)$, other primary headaches $(1.5 \%)$ ] were assigned to one of four treatment modules differing with regard to the number and types of interventions entailed (e.g., medication, psychological intervention, physical therapy, etc.). A rather simple assignment algorithm based on headache frequency, medication use and psychiatric comorbidity was used. Patients in the different modules were compared with regard to the experienced burden of disease. 1-year follow-up outcome data are reported $(N=160)$. Headache frequency and analgesic consumption differed significantly among patients in the modules. Headache-related disability was highest in patients with high headache frequency with/without medication overuse or psychiatric comorbidity (modules 2/3) compared to patients with low headache frequency and medication
\end{abstract}

T.-M. Wallasch and C. Hermann contributed equally to this paper.

T.-M. Wallasch

Headache Center Berlin at the Sankt

Gertrauden Krankenhaus Berlin, Berlin, Germany

T.-M. Wallasch ( $\square)$

MEDAS Ostschweiz, Interdisciplinary Medicine,

Kornhausstr. 3, 9000 St. Gallen, Switzerland

e-mail: TomWallasch@aol.com

C. Hermann $(\bowtie)$

Department of Clinical Psychology,

Justus-Liebig University Giessen, Giessen, Germany

e-mail: christiane.hermann@psychol.uni-giessen.de (module 0). Physical functioning was lowest in patients with chronic headache regardless of additional problems (modules $1 / 2 / 3$ ). Psychological functioning was lowest in patients with severe chronicity with/without additional problems (module $2 / 3$ ) compared to headache suffers with no/moderate chronicity (module $0 / 1$ ). Anxiety or depression was highest in patients with severe chronicity. In 1-year follow-up, headache frequency (minus $45.3 \%$ ), consumption of attack-aborting drugs (minus $71.4 \%$ ) and headache-related disability decreased (minus $35.9 \%$ ). Our results demonstrate the clinical effectiveness and the criterion validity of the treatment assignment algorithm based on headache frequency, medication use and psychiatric comorbidity.

Keywords Integrated care - Multidisciplinary modularized treatment program - Outcome study . Headache-related disability .

Headache-related quality of life $\cdot$ Chronic headache

\section{Introduction}

Headache (HA) is one of the most common types of chronic pain. In adults, about $4 \%$ experience HA episodes on a near daily or daily basis [1]. Chronic headache imposes an immense burden on the individual and society because of significant morbidity and indirect and direct costs. The annual value of lost productivity in the United States is estimated to reach $\$ 13$ billion for migraine and $\$ 19$ billion for all headache disorders $[2,3]$. Headache-related disability (HRD) is reported by more than $85 \%$ of migraineurs. Headaches reduce the quality of life, decrease social and job functioning, and increase utilization of health care systems [4, 5]. Accordingly, the World Health Organization (WHO) has ranked migraine among the top 20 most disabling medical diseases worldwide [6]. 
Despite advances in the acute and preventive treatment of primary headaches, many headache patients remain misdiagnosed and undertreated [7-10]. Headache sufferers are often dissatisfied with the health care they receive. On average, patients with chronic headache utilize more health care resources than patients with other chronic diseases, for example consuming twice as much medication $[11,12]$.

Cross-sectional and longitudinal epidemiological studies as well as clinical studies, family and twin studies have repeatedly reported a high comorbidity between headache and mood and anxiety disorders. Psychiatric disorders may interfere with headache treatment. HA patients with a comorbid mood or anxiety disorders report lower healthrelated quality of life (HRQoL) [13, 14], have a poorer prognosis and respond less well to treatment. The prevalence and impact of psychiatric disorders in headache patients underline the necessity for screening patients as part of routine clinical care and not only of refractory patients in tertiary headache centers [15].

In clinical practice, there is a lack of multidisciplinary headache treatment programs that entail a comprehensive assessment including a headache diagnosis according to ICDH-II criteria [16], screening for psychiatric comorbidity, craniomandibular dysfunctioning and musculoskeletal disorders, and provide treatment according to clinical guidelines [17, 18]. Unfortunately, little is known about such integrated headache programs and the patients participating in such programs [19, 20].

In 2005, Diener and co-workers launched the West German Headache Center, a managed and modularized healthcare system for chronic headache patients [21, 22] that was rated by the Harvard business school as one of the best medical programs worldwide [23]. Later, centers in Berlin, Munich and Jena followed. Primarily, this paper focuses on the validity of patient assignment to the treatment modules of our integrated headache care program. Specifically, patients in the different modules were compared with regard to pain-related disability, health-related quality of life and psychological distress. For a subset of patients, we also report 1-year follow-up data of patients with frequent or difficult to treat headaches. Detailed data on the program's cost-effectiveness have been reported elsewhere [24].

\section{Methods}

The Headache Center Berlin (HCB)

The Headache Center Berlin started in 07/2006 as a tertiary outpatient headache clinic. Treatment is multidisciplinary with daily treatment sessions. Additional inpatient treatment facilities ( 5 beds) are available for patients with medication overuse and severe psychiatric comorbidity. The HCB cooperates with a network of primary care physicians and headache specialists (secondary care). All network partners are connected with the HCB by specifically designed online documentation software [25]. At the HCB, European Headache Federation guidelines for the organization of headache clinics are implemented [26].

\section{Study design}

This prospective study was done to evaluate the new treatment approach used in the HCB. Adult patients (>18 years) with frequent andlor difficult to treat headache diagnoses of migraine $(M)$, tension-type headache (TTH), and medication overuse headache (MOH) were consecutively enrolled within a time period of 18 months (11/2006-04/2008). Headache diagnoses were made according to ICHD-II criteria [16] by a board-certified neurologist (TMW). The baseline data of the total cohort were used for determining the validity of treatment assignment. A representative subgroup of these patients completed treatment during this time period. For these, we report the 1-year follow-up data. The remaining patients followed the treatment program. A reduction of headache frequency (days with headache/month) of $\geq 50 \%$ was defined as treatment success and served as primary outcome parameter. Secondary outcomes were changes in headache-related disability, anxiety and depression and analgesic use. All patients signed a written informed consent form. The project was approved by the local Ethics Committee.

\section{Assessment}

Patients were referred by physicians or specialists when headache treatment failed. In addition, health insurance companies identified eligible patients on the basis of inpatient data, sick leave or records of prescribed medication. Finally, self-referrals were encouraged by media coverage. Patients kept a headache diary for at least 4 weeks prior to the first study visit. All patients underwent an initial comprehensive assessment by a neurologist, a psychologist and a physical therapist, and completed several questionnaires assessing mood, headache-related disability and health-related quality of life (see below for details). A detailed headache history was taken, patients underwent a physical exam, and a HA diagnosis was made according to ICHD-II criteria [16]. If necessary, additional diagnostic tests (imaging, blood test, etc.) were run. The psychologist obtained information about the patient's level of stress, emotional well-being, job satisfaction, life events, and data on possible psychological HA triggers were collected. Mental disorders were assessed based on ICD-10 
[27], which is the standard classification system used in the German health system. A physical therapist examined posture and muscle function. Subsequent to the assessment, both team and patient met in a pain conference and made a joint decision about further treatment.

\section{Treatment}

As stated earlier, the managed care system entails a modularized treatment protocol. Patients were assigned to one of four treatment modules taking into consideration headache frequency, medication overuse and psychiatric comorbidity. Typically, treatment duration is 1 year.

Module 0: no or little chronicity

Patients assigned to module 0 have a maximum of $5 \mathrm{HA}$ days/month. Patients are referred back to primary care physicians with recommendation for improved headache management (e.g. change of medication).

Module 1: moderate chronicity

Patients with a HA frequency between 6 and $<10$ HA days/ month and $<10$ days with intake of analgesics/triptans are assigned to this module. Treatment includes education and patient self-management for preventing headache episodes. Medication is optimized if necessary.

\section{Module 2: severe chronicity}

Patients with more than 10 HA days/month and more than 10 days with intake of analgesics/triptans are assigned to module 2. Patients receive module 1 treatment with a maximum of 12 additional outpatient sessions on 5 consecutive days from 9.00 a.m. to 4.00 p.m. The program entails group sessions and individual appointments with the neurologist, psychologist and the physical therapist. The neurologist provides headache education ( $90 \mathrm{~min}$ per day). The psychologist provides cognitive-behavioral pain management. The physical training comprises endurance sport, physical therapy and Nordic walking (60 min per day).

Module 3: severe chronicity with additional problems

Patients with more than 15 HA days/month and more than 15 days with intake of analgesics/triptans and severe psychiatric comorbidity are assigned to this module. Aside from participating in the outpatient program of module 2 , they are hospitalized for 5 up to a maximum of 7 days and undergone drug withdrawal. Treatment entails initiating adequate acute and prophylactic drug management.

\section{Study patients}

During a time period of 18 months (11/2006-04/2008), a cohort of 545 headache sufferers was consecutively referred to the HCB, which started in 07/2006 with a new modularized headache managed care program. Baseline data of these patients $(N=545)$ were available for validation of criterion-based patient assignment to the present modularized headache treatment program. With the exception of patients suffering from medication overuse headache, patients with secondary headaches were excluded. Of the total cohort, $N=83$ patients were assigned to module $0, N=158$ patients to module $1, N=249$ to module 2 and $N=55$ patients to module 3 .

During the 18 -month study period $N=160$ patients completed the treatment, while the remaining patients followed treatment program. For these, 12-month followup outcome data are reported. Of these, $N=47(29.4 \%)$ had been assigned to module $1, N=97(60.6 \%)$ to module 2 and $N=16(10 \%)$ to module 3 .

\section{Questionnaires}

All questionnaires were administered on a pocket PC using AC-STB software from Akkaya company, Köln, Germany $[24,25]$.

\section{Headache-related disability}

The Migraine Disability Assessment (MIDAS) Questionnaire $[28,29]$ was developed to assess headache-related disability. It contains five questions assessing the number of missed days (full or with substantial loss of productivity) at work, household chores, and leisure time. Reliability and validity of the MIDAS have extensively been demonstrated [28-30]. The total MIDAS score can be used to grade migraine-related disability [grade 1 (minimal disability): $1-5$ points, grade 2 (mild): $6-10$ points, grade 3 (moderate): 11-20 points, grade 4 (severe): $>20$ points] [28]. Headache frequency (past 3 months) and intensity are assessed by two additional MIDAS items.

\section{Chronic Pain Grade Questionnaire (CPGQ)}

The CPGQ [31] consists of 6 items assessing pain intensity or disability on 11-point numerical rating scales ranging from " 0 " to " 10 ". In addition, the number of days with disability during the past 3 months is obtained. Using an empirically derived and validated grading system, severity is divided into five categories: grade 0 (pain free), grade 1 (low disability, low-pain intensity), grade 2 (low disability, high-pain intensity); grade 3 (high disability, moderately 
limiting pain); and grade 4 (high disability, severely limiting pain). Reliability and validity of the CPGQ have been shown for the German version [32].

Health-related quality of life (HRQoL)

Health-related quality of life was assessed using the German version of the 12 item-Short Form Health Survey (SF12 [33], German version: [34]). The SF12 contains 2 subscales of functioning ("physical"/"psychological"). The SF12 is reliable and valid, norms for the general population are available [34].

Anxiety and depression

The Hospital Anxiety and Depression Scale (HADS, (German: [35]) contains seven items each for assessing depression and anxiety. The HADS is recommended for patients with somatic problems [14]. In its original version, a score between 0 and 7 is considered to be in the normal range, a score between 8 and 10 as being slightly elevated, and a score of 11 and higher as indicating the probable presence of a mood or anxiety disorder.

\section{Data analysis}

Depending on the type of outcome variable, differences between modules were computed either with one-way analysis of variances (ANOVA) followed by Tukey's HSD post hoc tests for all pairwise contrasts or by chi-square tests. Treatment data were computed either with Student $t$ test or Mann-Whitney $U$ test when variables were not normally distributed. All analyses were performed using Predictive Analytics SoftWare (PASW) by SPSS. A $p$ value of 0.05 was considered as significant.

Table 1 Sociodemographic data and clinical characteristics of all headache patients

\begin{tabular}{|c|c|c|c|c|c|}
\hline & $\begin{array}{l}\text { Total } \\
(N=545)\end{array}$ & $\begin{array}{l}\text { Module } 0 \\
(N=83)\end{array}$ & $\begin{array}{l}\text { Module } 1 \\
(N=158)\end{array}$ & $\begin{array}{l}\text { Module } 2 \\
(N=249)\end{array}$ & $\begin{array}{l}\text { Module } 3 \\
(N=55)\end{array}$ \\
\hline Age (year; $M, \mathrm{SD}$ ) & $43.08(12.94)$ & $42.70(13.15)$ & $43.94(12.61)$ & $42.50(12.89)$ & $43.90(13.94)$ \\
\hline$N$, females $(\%)$ & $489(89.7)$ & $77(92.8)$ & $145(91.8)$ & $222(89.2)$ & $45(81.8)$ \\
\hline \multicolumn{6}{|l|}{ HA diagnosis $(\%)$} \\
\hline Migraine $^{\mathrm{A}}$ & $293(53.8)$ & $55(66.3)$ & $90(57.0)$ & $118(47.4)$ & $30(54.5)$ \\
\hline Tension-type HA $(\%)^{\mathrm{A}}$ & $43(8.3)$ & $3(3.6)$ & $6(3.8)$ & $32(12.9)$ & $4(7.3)$ \\
\hline Migraine $+\mathrm{TTH}(\%)^{\mathrm{A}}$ & $164(30.1)$ & $21(25.3)$ & $55(34.8)$ & $73(29.3)$ & $15(27.3)$ \\
\hline Migraine + other HA disorders $(\%)^{\mathrm{B}}$ & $13(2.4)$ & $1(1.2)$ & $1(0.6)$ & $10(4.0)$ & $1(1.8)$ \\
\hline $\mathrm{TTH}+$ other HA disorders $(\%)^{\mathrm{B}}$ & $3(0.6)$ & $0(0)$ & $0(0)$ & $2(0.8)$ & $1(1.8)$ \\
\hline $\begin{array}{l}\text { Migraine }+\mathrm{TTH}+\text { other HA disorders } \\
(\%)^{\mathrm{B}}\end{array}$ & $1(0.2)$ & $1(1.2)$ & $0(0)$ & $0(0)$ & $0(0)$ \\
\hline Other HA disorders $(\%)^{\mathrm{B}}$ & $16(2.9)$ & $1(1.2)$ & $5(3.2)$ & $9(3.6)$ & $1(1.8)$ \\
\hline $\mathrm{MOH}$ only $(\%)^{\mathrm{C}}$ & $8(1.5)$ & $0(0)$ & $0(0)$ & $5(2.0)$ & $3(5.5)$ \\
\hline $\mathrm{MOH}($ w/o other HA disorders; \%) & $23(4.2)$ & $0(0)$ & $3(1.9)$ & $13(5.2)$ & $7(12.7)$ \\
\hline HA duration (year; M, SD) & $20.69(12.65)$ & $19.85(13.01)$ & $22.09(12.28)$ & $19.59(12.92)$ & $22.86(11.52)$ \\
\hline \multicolumn{6}{|l|}{ MIDAS (M, SD) } \\
\hline Headache frequency (last 3 months) & $28.43(23.11)$ & $8.45^{\mathrm{a}}(3.76)$ & $22.39^{\mathrm{b}}(9.62)$ & $35.59^{\mathrm{c}}(25.66)$ & $43.55^{\mathrm{d}}(29.64)$ \\
\hline Headache intensity (last 3 months) & $6.37(2.00)$ & $6.40^{\mathrm{a}}(2.12)$ & $6.42^{\mathrm{a}}(1.82)$ & $6.32^{\mathrm{a}}(2.07)$ & $6.42^{\mathrm{a}}(2.04)$ \\
\hline Analgesic use ( $N$ days/month, $\mathrm{M}, \mathrm{SD}$ ) & $8.84(10.24)$ & $4.48^{\mathrm{a}}(4.91)$ & $6.47^{\mathrm{a}}(6.96)$ & $9.13^{\mathrm{b}}(8.93)$ & $20.85^{\mathrm{c}}(17.9)$ \\
\hline Medication doses ( $N$ per months; $\mathrm{M}, \mathrm{SD})$ & $18.77(28.58)$ & $8.99^{\mathrm{a}}(4.91)$ & $12.96^{\mathrm{a}}(10.8)$ & $17.53^{\mathrm{a}}(17.1)$ & $55.8^{\mathrm{b}}(69.34)$ \\
\hline
\end{tabular}

Differences between modules were computed either with one-way analysis of variances (ANOVA [49]) or with $\chi^{2}$ tests, depending on the type of variable. Means with different lowercase superscripts differ significantly (Tukey's HSD)

$H A$ headache, $M O H$ medication overuse headache, $T T H$ tension-type HA

${ }^{+}$Headache diagnosis was missing for two patients, one each in modules 0 and 1 . Hence, percent values do not add up to 100

A With or without $\mathrm{MOH}$

B Other HAs refer to all HA diagnoses except $\mathrm{MOH}$

C Underlying primary headache not definable

D This refers to the total number of patients with an $\mathrm{MOH}$ diagnosis in the total sample or the modules 


\section{Results}

Study sample

Table 1 shows sociodemographics, diagnoses and headache characteristics at baseline of the total cohort. There were no significant differences in headache diagnoses, headache characteristics and sociodemographics of the subgroup of treated patients in comparison with the total cohort.

\section{Comparison of modules}

There was no significant difference between patients in the four modules with regard to age $(p>0.5)$ and sex proportion $(p>0.15)$. The vast majority of patients suffered from migraine alone or in combination with tension-type or other headaches. For the past 3 months, patients reported on average a headache frequency of $28.43 \pm 23.11$ days which differed significantly across groups $(\mathrm{F}(3,541)=$ 51.16, $p<0.001)$. As illustrated in Table 1 and confirmed by significant pairwise post hoc contrasts, headache frequency increased significantly from modules 0 to 1,1 to 2 , and 2 to 3 . Headache intensity was on average $6.37 \pm 2.00$ with no significant difference between modules $(p>0.9)$. Patients relied on analgesics on an average of $8.84 \pm$ 10.24 days per month. Analgesic uses varied significantly across modules $(\mathrm{F}(3,539)=40.35, p<0.001)$ with patients in modules 0 and 1 using significantly less analgesics than patients in modules 2 and 3 , and patients in module 3 having a significantly more frequent use than patients in module 2 (see Table 2). Patients reported an average consumption of medication doses of $6.34 \pm 10.15$ per month which varied significantly across the modules $(\mathrm{F}(3,539)=44.14, p<0.001)$ with patients in module 3 using the greatest amount of medication compared to all other patients. Patients in modules 0,1 and 2 did not significantly differ with regard to the number of medication doses.

Headache-related disability

The MIDAS total score differed significantly between modules $(\mathrm{F}(3,541)=23.14, p<0.001)$. Post hoc Tukey contrasts revealed that patients in module 0 had a significantly lower MIDAS total score compared to all other patients. Patients in module 1 had significantly lower MIDAS total scores than patients in modules 2 and 3, with the latter two not differing significantly (see Table 2). Consistently, the percentage of patients having a MIDAS grade III or IV increased significantly from module 0 to module $3\left(\chi^{2}(9)=49.4, p<0.001\right.$; see Table 2).

\section{Chronic Pain Grading Questionnaire (von Korff index)}

Similar to the MIDAS grades, the von Korff grades of severity differed significantly between modules $\left(\chi^{2}(9)=\right.$ 47.03, $p<0.001$; see Table 2). The proportion of patients with a severity grade of III or IV increased from modules 0 $(27 \%)$ to $3(72 \%)$ with modules $1(50 \%)$ and $2(57 \%)$ lying in between.

Anxiety and depression

One-way ANOVAs revealed significant differences with regard to HADS anxiety $(\mathrm{F}(3,541)=23.84, p<0.001)$ and depression scores $(\mathrm{F}(3,541)=22.94, p<0.001)$. Post hoc contrasts (Tukey HSD) showed that anxiety and depression levels of patients in modules 0 and 1 were not significantly different. However, both groups reported

Table 2 Pain-related disability (MIDAS, von Korff index)

\begin{tabular}{|c|c|c|c|c|c|}
\hline & Total & Module 0 & Module 1 & Module 2 & Module 3 \\
\hline \multicolumn{6}{|l|}{ MIDAS } \\
\hline Total score $(M, \mathrm{SD})$ & $43.43(42.44)$ & $18.49^{\mathrm{a}}(17.20)$ & $33.77^{\mathrm{b}}(29.12)$ & $53.9^{\mathrm{c}}(48.52)$ & $61.42^{\mathrm{c}}(48.55)$ \\
\hline Grade $1(N, \%)$ & 63 (11.6) & $19(22.9)$ & $16(10.1)$ & $26(10.4)$ & $2(3.6)$ \\
\hline Grade $2(N, \%)$ & $58(10.6)$ & $15(18.1)$ & $21(13.3)$ & $16(6.4)$ & $6(10.9)$ \\
\hline Grade $3(N, \%)$ & $79(14.5)$ & $22(26.5)$ & $21(13.3)$ & $32(12.9)$ & $4(7.3)$ \\
\hline Grade $4(N, \%)$ & $345(63.3)$ & $27(32.5)$ & $100(63.3)$ & $175(70.3)$ & $43(78.2)$ \\
\hline \multicolumn{6}{|l|}{ CPGQ (von Korff) } \\
\hline Grade $1(N, \%)$ & $138(25.3)$ & $39(47.0)$ & $43(27.2)$ & $50(20.1)$ & $6(10.9)$ \\
\hline Grade $2(N, \%)$ & $122(22.4)$ & $21(25.3)$ & $36(22.8)$ & $56(22.5)$ & $9(16.4)$ \\
\hline Grade $3(N, \%)$ & $212(38.9)$ & $22(26.5)$ & $63(39.9)$ & $97(39.0)$ & $30(54.5)$ \\
\hline Grade $4(N, \%)$ & 73 (13.4) & $1(1.2)$ & $16(10.1)$ & $46(18.5)$ & $10(18.2)$ \\
\hline
\end{tabular}

Differences between modules were computed either with one-way analysis of variances (ANOVA [49]) or $\chi^{2}$ tests, depending on the type of variable. Means with different superscripts differ significantly (Tukey's HSD) 
Table 3 Anxiety, depression and health-related quality of life (SF12) $(M$; SD) in the patients assigned to the four modules

\begin{tabular}{|c|c|c|c|c|c|}
\hline & Total & Module 0 & Module 1 & Module 2 & Module 3 \\
\hline \multicolumn{6}{|l|}{ HADS-Anxiety } \\
\hline Total score $(M, \mathrm{SD})$ & $7.13(3.95)$ & $5.23^{\mathrm{a}}(2.9)$ & $5.85^{\mathrm{a}}(3.35)$ & $8.35^{\mathrm{b}}(3.99)$ & $8.18^{\mathrm{b}}(4.53)$ \\
\hline$T$ score $(M, \mathrm{SD})$ & $54.85(11.4)$ & $49.46(9.68)$ & $51.23(10.58)$ & $58.34(10.94)$ & $57.57(12.00)$ \\
\hline Above cutoff $(N, \%)$ & $114(20.9)$ & $4^{\mathrm{a}}(4.8)$ & $17^{\mathrm{b}}(10.8)$ & $76^{\mathrm{c}}(30.5)$ & $18^{\mathrm{d}}(32.7)$ \\
\hline \multicolumn{6}{|l|}{ HADS—depression } \\
\hline Total score $(M, \mathrm{SD})$ & $5.57(3.93)$ & $3.7^{\mathrm{a}}(2.52)$ & $4.31^{\mathrm{a}}(3.52)$ & $6.69^{\mathrm{b}}(4.06)$ & $6.91^{\mathrm{b}}(4.12)$ \\
\hline $\mathrm{T}$ score $(M, \mathrm{SD})$ & $59.99(11.48)$ & $54.55(8.89)$ & $56.13(11.2)$ & 63.37 (10.99) & $64.00(11.46)$ \\
\hline Above cutoff $(N, \%)$ & $67(12.3)$ & $1^{\mathrm{a}}(1.2)$ & $17^{\mathrm{b}}(10.8)$ & $44^{\mathrm{c}}(17.7)$ & $11^{\mathrm{d}}(20.0)$ \\
\hline \multicolumn{6}{|l|}{ SF-12 $(M, \mathrm{SD})$} \\
\hline Physical & $40.02(8.00)$ & $43.62^{\mathrm{a}}(6.50)$ & $40.35^{\mathrm{b}}(7.62)$ & $39.08^{\mathrm{b}}(8.24)$ & $37.88^{\mathrm{b}}(8.47)$ \\
\hline Psychological & $45.08(10.62)$ & $50.13^{\mathrm{a}}(8.33)$ & $40.08^{\mathrm{a}}(9.40)$ & $42.07^{\mathrm{b}}(10.97)$ & $42.47^{\mathrm{b}}(10.38)$ \\
\hline
\end{tabular}

Differences between modules were computed either with one-way analysis of variances (ANOVA [49]) or $\chi^{2}$ tests, depending on the type of variable. Means with different superscripts differ significantly (Tukey's HSD)

HADS Hospital Anxiety and Depression Scale, SF-12 12 item version of the Short Form of Medical Outcomes Questionnaire

significantly less anxiety and depressive symptoms than patients in modules 2 and 3, with the latter not differing significantly. Correspondingly, the percentage of patients with a HADS anxiety $\left(\chi^{2}(3)=40.06, p<0.001\right)$ or depression score $\left(\chi^{2}(3)=23.34, p<0.001\right)$ above the cutoff of 11 differed significantly between modules, with the patients in modules 2 and 3 being most likely to have an anxiety or mood disorder (see Table 3 ).

Health-related quality of life

With regard to physical HQoL, patients in module 0 reported a significantly higher level compared to the patients in all other modules, with no significant difference between modules 1,2 and $3(\mathrm{~F}(3,541)=8.45, p<0.001$; see Table 3). With regard to psychological HQoL, the oneway ANOVA also revealed a significant group main effect $(\mathrm{F}(3,541)=20.18, p<0.001)$. Similar to the findings obtained for the HADS, the post hoc Tukey HSD contrasts showed that patients in modules 0 and 1 reported a similar level of psychological HQoL which was significantly lower than in modules 2 and 3 patients which, in turn, were not significantly different.

One-year follow-up

Mean reduction in HA frequency was 6.8 days/month. Headache frequency decreased from $15.00 \pm 8.19$ to $8.22 \pm 8.63(-45.3 \%)$ days/month $(t=5.056, d f=157$, $p<0.001) .61 .1 \%$ of the patients $(96 / 157)$ experienced a reduction of HA frequency ( $N$ HA days per month) of greater than $50 \%$. Headache-related disability (MIDAS) decreased significantly from $55.96 \pm 61.28$ to $35.87 \pm 55.09$ $(t=4.924, d f=129, p<0.001)$. HADS anxiety was also significantly lower at the 1-year follow-up (pre: $M=$ $7.60 \pm 4.24 ; \quad$ follow-up: $M=6.66 \pm 4.24 ; \quad t=2.567$, $d f=91, p=0.012$ ). The level of depressive symptoms (HADS) did not change significantly (pre: $M=5.70 \pm$ 3.77; follow-up: $M=5.10 \pm 4.54$ ). Medication (analgesics, triptans, ergotamine) was used by $98.7 \%$ of the patients at baseline and by $89.9 \%$ of patients at the 1-year follow-up with a highly significant reduction in the number of days with medication use per month (pre: $M=$ $10.92 \pm 7.31$; follow-up: $3.99 \pm 3.62 ;(t=9.686, d f=157$, $p<0.000)$. At baseline, $24 \%$ of the patients reported an intake frequency of $\geq 15$ days/month. $57 \%$ of patients used acute medication on 6-14 days/month and $17.7 \%$ on 1-5 days/month. At the end of treatment, only $1.3 \%$ of the patients consumed acute medication on $\geq 15$ days/month, $23.4 \%$ relied on acute medication on 6-14 days/month. About two-thirds of the patients $(65.2 \%)$ used acute medication on 1 up to 5 days/month. The number of patients who abstained from acute medication increased from 1.3 to $10.1 \%$. The number of patients who abstained from acute medication increased significantly from $1.3 \%$ at baseline to $10.1 \%$ at the end of treatment $\left[\chi^{2}\right.$ $(61.348)=43.4 ; d f=9 ; p<0.001]$.

\section{Discussion}

Providing efficient multidisciplinary treatment for difficult to treat patients is a challenge. Few data exist on how to assign patients to treatment and on effectiveness of such a multidisciplinary integrated headache care program for patients with frequent $\mathrm{HAs}$, including $\mathrm{MOH}$. A modularized program was 
chosen, because this allows to tailor the treatment to an individual's needs, and because it is not the referring physician who assigns the patient to specific interventions but treatment assignment is based on a multidisciplinary assessment.

The primary goal of the present study was the validation of a criterion-based patient assignment to the modules of our integrated headache care program. Our results document that the algorithm used to assign the patients to treatment modules specifically designed to meet their need works. A main aim was to offer managed health care for out- and inpatients that is tailored individually using HA frequency, analgesic consumption, and psychiatric comorbidity as criteria for treatment indication. Most of the available interdisciplinary headache concepts only offer a standardized program which does not allow an individual adjustment based on patients' needs [36, 37]. We developed a modularized headache treatment program with the aim of treating chronic headache suffers according their burden of disease. Patients are assigned to treatment modules based on headache frequency, medication overuse and psychiatric comorbidity. Most crucially, it needs to be shown that this algorithm allows a valid patient assignment with regard to headache-related disability and quality of life. As was to be expected when HA frequency is used as assignment criterion, HA frequency rose significantly from modules 0 to 3 with a significant increase between each module. By contrast, HA intensity was comparable in all patients. Similarly, analgesic consumption differed significantly in the four modules. Patients assigned to module 3 reported significantly more days of analgesic consumption and medication doses per month than those in the other modules. Patients in module 2 relied on medication on significantly fewer days per month than those in module 3 , but on significantly more days than those in modules 0 and 1. The total number of medication doses per month did not differ significantly between modules 0,1 and 2 . These results show that the patients' assignment based on HA frequency and medication use was well efficient.

Importantly, we aimed at validating patients' assignment to the different treatment modules with regard to external criteria, such as headache-related disability and health-related quality of life. The average MIDAS total score was 43.3, ranging from 18.5 in module 0 to 61.4 in module 3. Overall, these MIDAS scores well match those previously reported for chronic headache sufferers [38, 39]. Disability in patients assigned to module 2 or 3 was comparable. However, these patients were significantly more disabled than patients in modules 0 and 1 , with patients in module 0 being also significantly less disabled than patients in module 1 . Correspondingly, the percentage of patients having a MIDAS grade III or IV increased significantly from module 0 to module 3 . A rather similar pattern was observed with regard to the von Korff chronic pain grade questionnaire. Hence, both MIDAS and CPGQ scores were highest in patients assigned to module 3 and lowest in patients assigned to module 0. Module 2 patients' disability was comparable to module 3 patients' if the MIDAS score was considered and comparable to module 1 patients' if the CPGQ score was used. This difference is most likely accounted for by the fact that MIDAS measures disability primarily based on the number of days of lost productivity (e.g., work), whereas the CPGQ relies on the perceived degree of disability. Given that patients are assigned to module 3 rather than 2 if there is psychiatric comorbidity and not due to differences in HA activity and use of medication, it is rather plausible that disability determined based on the number of lost days due to HA does not significantly differ between modules 2 and 3 . Consistent with the findings for HA disability, healthrelated quality of life also varied between modules. With regard to the SF12 physical scale, patients with no or little chronicity (module 0 ) reported a significantly higher level of health-related quality of life compared to the patients in all other modules. By contrast, psychological functioning (SF12 mental health scale) was highest in patients assigned to modules 0 (no or less chronicity) and 1 (moderate chronicity) and lowest in patients in modules 2 (severe chronicity) and 3 (severe chronicity with additional problems). This pattern suggests that a HA frequency of more than 5 days/month is associated with a distinct reduction in physical functioning, whereas psychological quality of life is strongly affected when HA frequency exceeds 10 days per month. However, there is increasing awareness that mood and anxiety disorders are positively correlated with chronification of headache [40-42]. The observed decrease in psychological functioning is most likely accounted for by elevated anxiety and depression levels. Such an interpretation is supported by the observed pattern of the anxiety and depression HADS scores. Patients in modules 0 and 1 had similar anxiety and depression levels and a similar number of patients had HADS scores above the cutoff. These patients were significantly less anxious and depressed than the patients in modules 2 and 3 , with no significant difference between them. Clearly, we had expected that patients assigned to module 3 would be significantly more anxious and depressed than all other patients, given that psychiatric comorbidity as assessed by a clinical psychologist is a primary criterion for a patient's assignment to module 3 . Our findings suggest that the HADS was suitable for detecting patients with clinically elevated levels of anxiety and depression. This has important clinical implications as it suggest that patients with frequent HAs should be routinely screened using the HADS. The observed relationship between high HA frequency, high use of analgesics, high pain-related disability and high emotional distress is consistent with previous 
observations that psychiatric comorbidity contributes to the chronicity and intractability of headache [41, 43].

A second aim of the present study was to provide preliminary data on the effectiveness of this modularized HA treatment program. In a subset of patients, the primary and secondary outcome variables improved significantly. Specifically, mean HA frequency decreased by about 6.8 days/ month. On average, HA frequency was reduced by $45.3 \%$. This success rate is similar to previous studies which reported improvements of about $35 \%$ (e.g. Lemstra et al. [44]: $33.6 \%$ at 3-month follow-up; Gaul et al. [21]: $34.3 \%$ at a follow-up time between 12 and 18 months after the end of treatment). The number of days with acute medication intake, known as predictor of $\mathrm{MOH}$ [45], was also significantly reduced. The percentage of patients who relied on non-pharmacological self-management strategies increased from about $1.3 \%$ at baseline to $10.1 \%$ after 1 year. At follow-up, only $1.3 \%$ of the patient used medication on more than 15 days per month, at baseline $24 \%$ of the patients showed this pattern of medication use. This reduction is impressive, because previous studies have reported relapse rates of drug withdrawal of up to $40 \%$ within 1 year [46-48].

Taken together, our study shows that using a simple algorithm, it is feasible to assign HA patients to treatment modules tailored to patients' needs. Such a treatment assignment to a modularized treatment program seems promising for an effective and cost-efficient treatment of chronic HA patients.

\section{Conflict of interest None.}

Open Access This article is distributed under the terms of the Creative Commons Attribution License which permits any use, distribution, and reproduction in any medium, provided the original author(s) and the source are credited.

\section{References}

1. Scher AI, Midgette LA, Lipton RB (2008) Risk factors for headache chronification. Headache 48:16-25

2. Hu XH, Markson LE, Lipton RB, Stewart WF, Berger ML (1999) Burden of migraine in the United States: disability and economic costs. Arch Intern Med 159:813-818

3. Osterhaus JT, Gutterman DL, Plachetka JR (1992) Healthcare resource and lost labour costs of migraine headache in the US. Pharmacoeconomics 2:67-76

4. Stovner L, Hagen K, Jensen R, Katsarava Z, Lipton R, Scher A, Steiner T, Zwart JA (2007) The global burden of headache: a documentation of headache prevalence and disability worldwide. Cephalalgia 27:193-210

5. Smith R (1998) Impact of migraine on the family. Headache 38:423-426

6. Leonardi M, Steiner TJ, Scher AT, Lipton RB (2005) The global burden of migraine: measuring disability in headache disorders with WHO's Classification of functioning, disability and health (ICF). J Headache Pain 6:429-440
7. Pascual J, Lainez MJ, Baos V, Garcia ML, Lopez-Gil A (2007) Predictive model for the migraine-ACT questionnaire in primary care. Curr Med Res Opin 23:3033-3039

8. Lipton RB, Diamond S, Reed M, Diamond ML, Stewart WF (2001) Migraine diagnosis and treatment: results from the American Migraine Study II. Headache 41:638-645

9. Devine JW, Farley JF, Hadsall RS (2005) Patterns and predictors of prescription medication use in the management of headache: findings from the 2000 medical expenditure panel survey. Headache 45:1171-1180

10. Lipton RB, Stewart WF, Celentano DD, Reed ML (1992) Undiagnosed migraine headaches. A comparison of symptombased and reported physician diagnosis. Arch Intern Med 152:1273-1278

11. Barton CW (1994) Evaluation and treatment of headache patients in the emergency department: a survey. Headache 34:91-94

12. Clouse JC, Osterhaus JT (1994) Healthcare resource use and costs associated with migraine in a managed healthcare setting. Ann Pharmacother 28:659-664

13. Wang SJ, Fuh JL, Lu SR, Juang KD (2001) Quality of life differs among headache diagnoses: analysis of SF-36 survey in 901 headache patients. Pain 89:285-292

14. Maizels M, Smitherman TA, Penzien DB (2006) A review of screening tools for psychiatric comorbidity in headache patients. Headache 3:98-109

15. Baskin SM, Lipchik GL, Smitherman TA (2006) Mood and anxiety disorders in chronic headache. Headache 46:76-87

16. Headache Classification Subcommittee of the International Headache Society (2004) The International Classification of Headache Disorders: 2nd edition. Cephalalgia 24:9-160

17. Evers S, May A, Fritsche G, Kropp P, Lampl C, Limmroth V, Malzacher V, Sandor P, Straube A, Diener H-C (2008) Akuttherapie und Prophylaxe der Migräne-Leitlinie der Deutschen Migräne-und Kopfschmerzgesellschaft und der Deutschen Gesellschaft für Neurologie. Nervenheilkunde 27:933-949

18. Straube A, May A, Kropp P, Katsarava Z, Haag G, Lampl C, Sándor PS, Diener H-C, Evers S (2007) Therapie primärer chronischer Kopfschmerzen: Chronische Migräne, chronischer Kopfschmerz vom Spannungstyp und andere chronische tägliche Kopfschmerzen-Evidenzbasierte Empfehlungen der Deutschen Migräne-und Kopfschmerzgesellschaft in Zusammenarbeit mit der Österreichischen Kopfschmerzgesellschaft und der Schweizerischen Kopfwehgesellschaft. Nervenheilkunde 26:186-199

19. Cassidy EM, Tomkins E, Hardiman O, O'Keane V (2003) Factors associated with burden of primary headache in a specialty clinic. Headache 43:638-644

20. Jensen R, Zeeberg P, Dehlendorff C, Olesen J (2010) Predictors of outcome of the treatment programme in a multidisciplinary headache centre. Cephalalgia 30(10):1214-1224

21. Gaul C, van Doorn C, Webering N, Dlugay M, Katsarava Z, Diener HC, Fritsche G (2011) Clinical outcome of a headachespecific multidisciplinary treatment program and adherence to treatment recommendations in a tertiary headache center: an observational study. J Headache Pain 12:475-483

22. Gaul C, Bromstrup J, Fritsche G, Diener HC, Katsarava Z (2011) Evaluating integrated headache care: a one-year follow-up observational study in patients treated at the Essen headache centre. BMC Neurol 11:124

23. Porter ME, Guth C, Dannemiller E (2007) The West German Headache Center: integrated migraine care, Harvard Business School Publishing, Boston

24. Wollny M (2009) Integrierte Versorgung Kopfschmerz aus Sicht der Krankenkassen. Warum und wem hilft's? Nervenheilkunde 28:347-349

25. Wallasch TM, Bek J, Pabel R, Modahl M, Demir M, Straube A (2009) AC-STB-Eine sektorenübergreifende Software zur 
Dokumentation und Verlaufskontrolle von Kopfschmerzpatienten. Der Schmerz 2:145-153

26. Antonaci F, Valade D, Lanteri-Minet M, Lainez JM, Jensen R, Steiner TJ (2008) Proposals for the organisation of headache services in Europe. Intern Emerg Med 1:25-28

27. World Health Organization (1993) The ICD-10 classification of mental and behavioural disorders: diagnostic criteria for research

28. Stewart WF, Lipton RB, Whyte J, Dowson A, Kolodner K, Liberman JN, Sawyer J (1999) An international study to assess reliability of the migraine disability assessment (MIDAS) score. Neurology 53:988-994

29. Stewart WF, Lipton RB, Dowson AJ, Sawyer J (2001) Development and testing of the migraine disability assessment (MIDAS) questionnaire to assess headache-related disability. Neurology 56:20-28

30. Agosti R, Chrubasik JE, Kohlmann T (2008) Der Midas Fragebogen-Sprachliche Validierung der deutschen Version. Ars Medici 16

31. Von Korff M, Ormel J, Keefe FJ, Dworkin SF (1992) Grading the severity of chronic pain. Pain 50:133-149

32. Klasen BW, Hallner D, Schaub C, Willburger R, Hasenbring M (2004) Validation and reliability of the German version of the chronic pain grade questionnaire in primary care back pain patients. Psychosoc Med 1:Doc07

33. Ware J Jr, Kosinski M, Keller SD (1996) A 12-item short-form health survey: construction of scales and preliminary tests of reliability and validity. Med Care 34:220-233

34. Bullinger M, Kirchberger I (1998) Fragebogen zum Allgemeinen Gesundheitszustand SF12

35. Herrmann-Lingen C, Buss U, Snaith RP (2005) Hospital Anxiety and Depression Scale-Deutsche Version (HADS-D) (2.Aufl.)

36. Blumenfeld A, Tischio M (2003) Center of excellence for headache care: group model at Kaiser Permanente. Headache 43:431-440

37. Gunreben-Stempfle B, Griessinger N, Lang E, Muehlhans B, Sittl R, Ulrich K (2009) Effectiveness of an intensive multidisciplinary headache treatment program. Headache 49:990-1000

38. Bigal ME, Rapoport AM, Lipton RB, Tepper SJ, Sheftell FD (2003) Assessment of migraine disability using the migraine disability assessment (MIDAS) questionnaire: a comparison of chronic migraine with episodic migraine. Headache 43:336-342

39. D'Amico D, Grazzi L, Usai S, Rigamonti A, Curone M, Bussone G (2005) Disability pattern in chronic migraine with medication overuse: a comparison with migraine without aura. Headache 45:553-560

40. Lipton RB, Silberstein SD, Saper JR, Bigal ME, Goadsby PJ (2003) Why headache treatment fails. Neurology 60:1064-1070

41. Nicholson RA, Houle TT, Rhudy JL, Norton PJ (2007) Psychological risk factors in headache. Headache 47:413-426

42. Penzien DB, Rains JC, Andrasik F (2002) Behavioral management of recurrent headache: three decades of experience and empiricism. Appl Psychophys Biofeedback 27:163-181

43. Heckman BD, Holroyd KA, Himawan L, O’Donnell FJ, Tietjen G, Utley C, Stillman M (2009) Do psychiatric comorbidities influence headache treatment outcomes? Results of a naturalistic longitudinal treatment study. Pain 146:56-6443

44. Lemstra M, Stewart B (2002) Olszynski. Effectiveness of multidisciplinary intervention in the treatment of migraine: a randomized clinical trial. Headache 42:845-854

45. Katsarava Z, Muessig M, Dzagnidze A, Fritsche G, Diener HC, Limmroth V (2005) Medication overuse headache: rates and predictors for relapse in a 4 -year prospective study. Cephalalgia 25:12-15

46. Hagen K, Stovner LJ (2011) A randomized controlled trial on medication-overuse headache: outcome after 1 and 4 years. Acta Neurol Scand Suppl 191:38-43

47. Sances G, Ghiotto N, Galli F, Guaschino E, Rezzani C, Guidetti $\mathrm{V}$, Nappi G (2010) Risk factors in medication-overuse headache: a 1-year follow-up study (care II protocol). Cephalalgia 30(3): 329-336

48. Ghiotto N, Sances G, Galli F, Tassorelli C, Guaschino E, Sandrini G, Nappi G (2009) Medication overuse headache and applicability of the ICHD-II diagnostic criteria: 1-year follow-up study (CARE I protocol). Cephalalgia 29(2):233-243

49. David H (2002) Statistical methods for psychology. Duxbury, pp 324-325 